\title{
A RARE COMBINATION OF CONGENITAL BLINDNESS WITH PANHYPOPITUITARISM: CASE REPORT ON SEPTO-OPTIC DYSPLASIA
}

\author{
JAHAN $\mathrm{S}^{1}$, SULTANA N ${ }^{1}$, FARIDUDDIN $\mathrm{M}^{1}$, HOSSAIN MZ², HUSSAIN ME ${ }^{3}$, ALAM R ${ }^{1}$, HASANAT MA ${ }^{1}$
}

\begin{abstract}
:
Septo-optic dysplasia is a rare, heterogeneous condition characterized by a variable combination of Optic nerve hypoplasia, midline brain abnormalities and hypothalamic-pituitary endocrine dysfunction. ${ }^{1}$ Here the authors report a 19-yr-old Bangladeshi male who presented with features consistent with hypogonadism, marked visual impairment in both eyes and polyuria ç polydipsia due to DI (as confirmed biochemically). His karyotyping was a normal male (47,XY); His bone age was delayed by at least 3 yrs than his chronologic age. Fundal photography showed bilateral hypo plastic optic disc having 'double ring sign' and 'morning glory appearance' on left side. Hormonal assay proved panhypopituitarism with Hypogonadotrophic hypogonadism. MRI of the brain showed empty Sella and hypo plastic Optic Nerve. He was started on androgen and steroid replacement along with DDAVP spray for DI. Now he is on regular follow up and doing well.
\end{abstract}

Key Word: Septo-optic dysplasia (SOD), Panhypopituitarism, DI, Optic atrophy.

J Dhaka Med Coll. 2012; 21(1) : 124-128.

\section{Introduction:}

The term Septo-optic dysplasia (SOD) is widely used as a synonym for optic nerve hypoplasia. The term was first coined in 1956 by a Swiss neurologist, Georges De Morsier, who noted an association between optic nerve underdevelopment and the absence of septum pellucidum. However the term SOD is slowly losing favor with physicians and researcher because the presence or absence of septum pellucidum does not seem to be a defining aspect of the diagnosis. Optic Nerve Hypoplasia $(\mathrm{ONH})$ is now the preferred term. It is also called De Morsier Syndrome, in honor of its discoverer. ${ }^{2}$ The etiology and pathogenesis of SOD is not fully understood, but it is believed to be multifactoriual, involving both environmental and genetic factors. The frequent association of cerebral hemispheric abnormalities with optic nerve hypoplasia led to the hypothesis that there may be a disruption of neuronal guidance mechanism that regulates the migration of both cerebral hemispheric neurons and optic nerve axons in utero. ${ }^{3}$ It is a rare congenital anomaly and has a reported prevalence of 6.3 per 100,000 . It has a near equal distribution among males and females, and it is typically diagnosed in newborns and infants. ${ }^{4}$

\section{Case report:}

A 19-year-old Bangladeshi male (Fig-1) presented to Endocrinology OPD, BSMMU with lack of development of pubertal features and undersized genitalia. He was born full-term to a 30-year-old mother by uneventful vaginal delivery. At age of 2.5 years he had a self limiting febrile illness with single episode of generalized convulsion. He had a cleft lip that was corrected surgically at 3 years. His developmental milestones were normal, and intelligence as par age. At 6 years of age, as he started schooling, his parents noticed his marked difficulty with reading, and took him to an ophthalmology clinic. There he was noted to have significant visual impairment in right eye and near complete blindness in left eye, and high-powered spectacles were provided. At

1. Dr. Sharmin Jahan, Dr. Nusrat Sultana, Dr. Md. Fariduddin, Robiul Alam, Dr. MA Hasanat, Endocrine Wing, Department of Medicine, Bangabandhu Sheikh Mujib Medical University (BSMMU)

2. Dr. Mohammad Zaid Hossain, Assistant Professor, Department of Medicine, Dhaka Medical College, Dhaka 3. Dr. Mohammad Enayet Hussain, Department of Neurology, Dhaka Medical College Hospital (DMCH)

Correspondence : Dr. M A Hasanat, MBBS, M.Phil, MD, Associate Professor of Endocrine Medicine, Department of Medicine, BSMMU, Dhaka-1000, Bangladesh, E-mail: hasanatdr@yahoo.com 


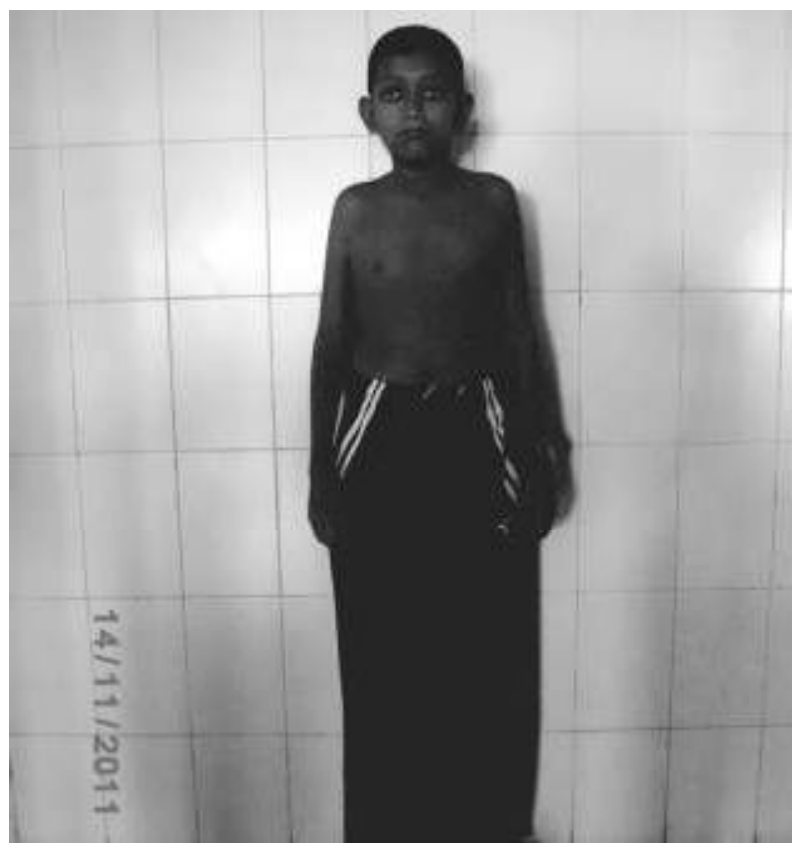

Fig.-1: Front profile of the patient.

that time he was noted to have marked polyuria (9-10 L/day) with associated polydipsia that interrupted sleep (intake 8-9 L/day). So, again he was examined by an endocrinologist and DI was his diagnosed following water deprivation test. Since then he is on DDAVP nasal spray with control of symptoms up-todate. This time he presented to us with lack of appearance of any secondary sexual characteristics, which made his parents worried enough to seek the advice of a doctor.

On physical examination, his height was $159 \mathrm{~cm}$, weight $41 \mathrm{~kg}$, BMI 16.21, arm span

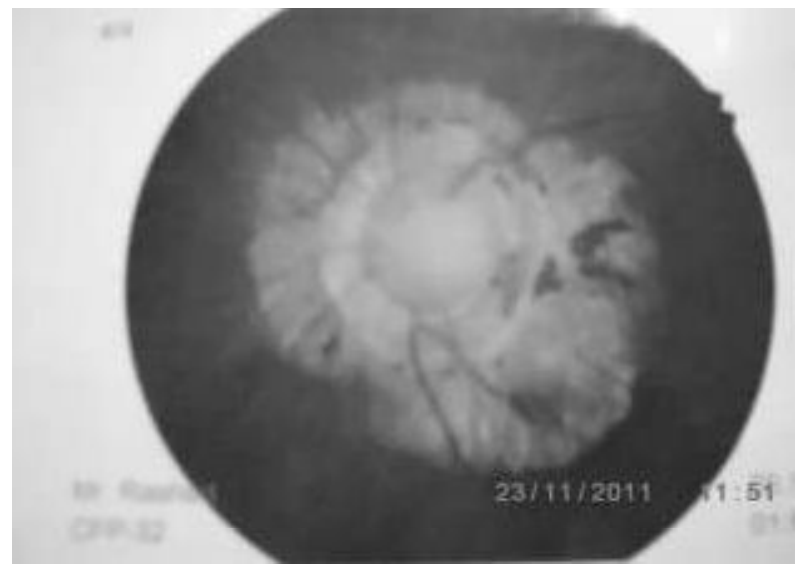

Fig.-2: Fundal photograph of left eye shows "Double ring sign."
$158 \mathrm{~cm}$, crown to pubis length $82 \mathrm{~cm}$, pubis to heel $77 \mathrm{~cm}$, upper to lower segment ratio of 1.06. He had high pitched voice, his skin was smooth and pale. He showed absence of any hair over the face, arms or legs. He lacked any masculine development of body parts. His pubic hair was sparse (Tanner stage-1), bilaterally small testes $(<3 \mathrm{~cm}$ on right and $<5 \mathrm{~cm}$ on left side using Prader orchidometer), micro phallus (stretched penile length $2.2 \mathrm{~cm}$ ). Neurologic examination was normal except $2_{\mathrm{ND}}$ cranial nerve which revealed: visual

acuity $6 / 28$ in right eye, finger counting in left eye with normal field of vision and color vision in both eyes, fundoscopy showed bilateral small and pale optic disc with sharp margin. Other systemic examination revealed no abnormality.

Initial hematological and biochemical work-up was normal including OGTT (FBS-4.2 mmol/L, 2 hour after $75 \mathrm{gm}$ glucose- $5.4 \mathrm{mmol} / \mathrm{L}$ ) and serum electrolyte (Na-145mmol/L, K$3.9 \mathrm{mmol} / \mathrm{L}, \mathrm{Cl}-99 \mathrm{mmol} / \mathrm{L}$, TCO2-28mmol/ L).Karyotyping was normal male.

Hormonal assay results included GH before and after exercise, serum ACTH and basal cortisol, short Synacthen test, FT4, TSH, serum LH, FSH, serum testosterone which revealed Panhypopituitarism and Hypogonadotrophic Hypogonadism (table-1).

\section{Table-I}

\begin{tabular}{lcc}
\hline Hormonal Assay & Result & Normal Value \\
\hline GH( before exercise) & $0.065 \mathrm{ng} / \mathrm{ml}$ & $<5 \mathrm{ng} / \mathrm{mlGH}($ \\
after exercise) & $0.075 \mathrm{ng} / \mathrm{ml}$ & $<1 \mathrm{n} \mathrm{g} / \mathrm{m} \mathrm{l}$ \\
S.ACTH & $11.4 \mathrm{pg} / \mathrm{ml}$ & $3-52 \mathrm{pg} / \mathrm{ml}$ \\
Basal Cortisol & $37.5 \mathrm{nmol} / \mathrm{L}$ & $221-690 \mathrm{nmol} /$ \\
LS.LH & $1.77 \mathrm{mIU} / \mathrm{ml}$ & $0.95-5.60 \mathrm{mIU} / \mathrm{ml}$ \\
S.FSH & $1.35 \mathrm{mIU} / \mathrm{ml}$ & $1-8 \mathrm{miu} / \mathrm{ml}$ \\
S. Testosterone & $29.4 \mathrm{ng} / \mathrm{dl}$ & $260-1000 \mathrm{ng} / \mathrm{dl}$ \\
FT 4 & $1.10 \mathrm{ng} / \mathrm{ml}$ & $0.8-2.7 \mathrm{ng} / \mathrm{dl}$ \\
TSH & $0.54 \mu \mathrm{IU} / \mathrm{ml}$ & $0.4-5.50$ \\
S.Prolactin & $11.82 \mathrm{ng} / \mathrm{ml}$ & $2-18 \mathrm{ng} / \mathrm{ml}$ \\
\hline
\end{tabular}


X-ray knee and wrist joint showed bone age below 16 years( Fig-3). Fundal photograph was taken, it showed bilateral hypo plastic pale disc with clearcut margin and presence of peri-papillary atrophy, double ring sign and morning glory appearance on left side( Fig-.MRI of brain showed empty Sella

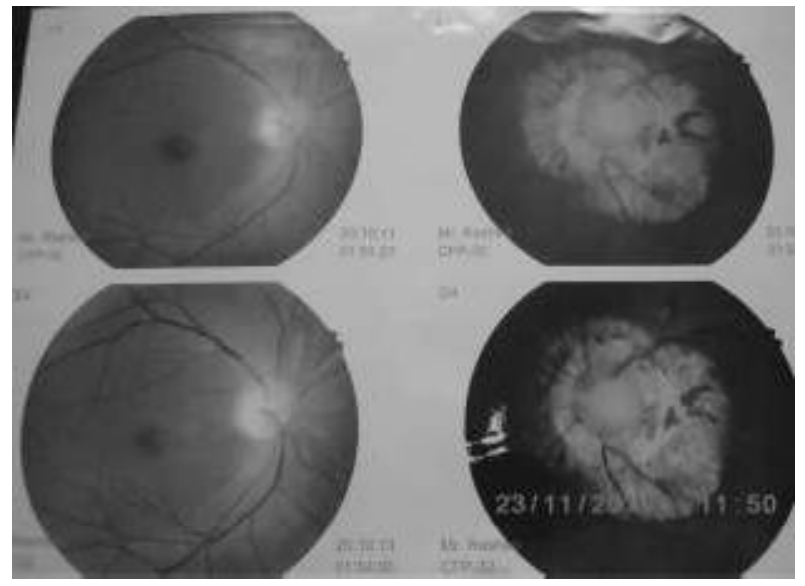

Fig.-3: Fundal photograph

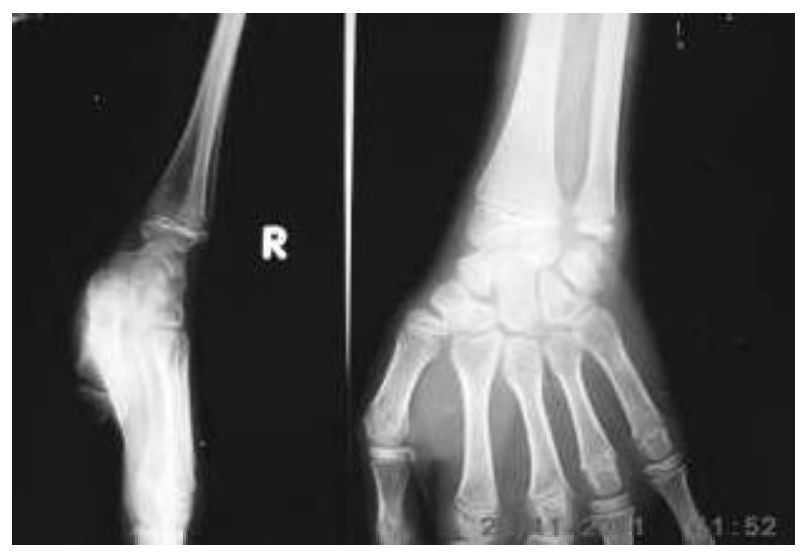

Fig.-4: X-ray left wrist joint

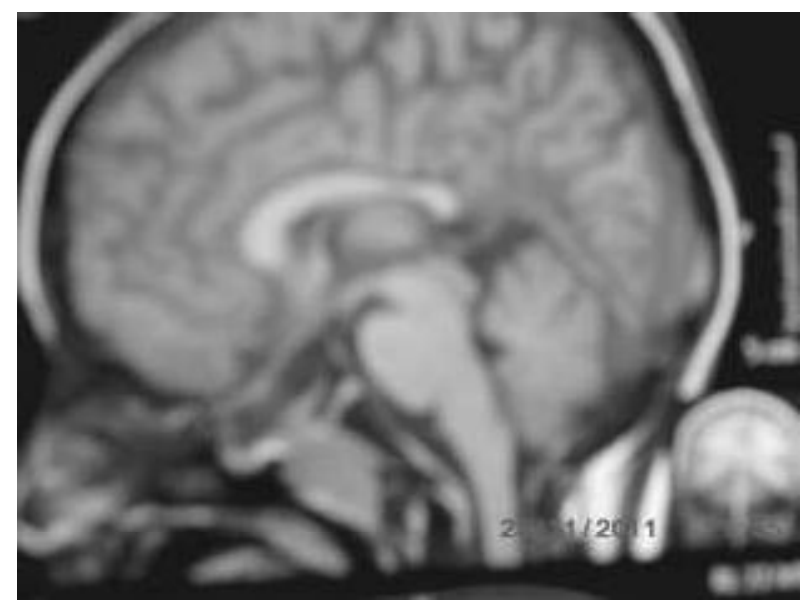

Fig.-5: MRI of brain (sagittal view) shows Empty Sella

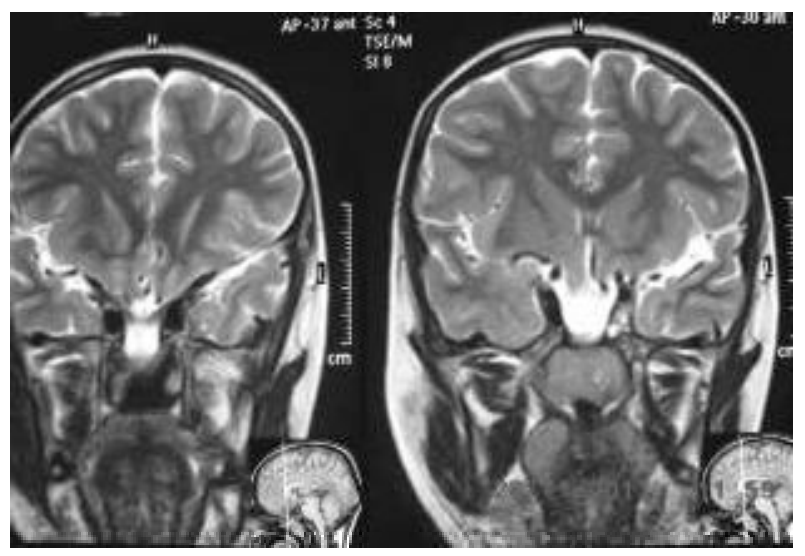

Fig.-6: MRI of Brain (Coronal view) shows Empty Sella

He was started on androgen replacement with 3 weekly testosterone injections to induce development of secondary characteristics which was the immediate goal. Along with it he was given steroid replacement and DDAVP spray for treatment of secondary hypocortisolism and DI. He was provided with a steroid card and counseled accordingly.

\section{Discussion:}

Septo-Optic Dysplasia is a rare congenital abnormality characterized by optic nerve hypoplasia in conjunction with midline brain abnormalities, the absence of the septum pellucidum and agenesis or thinning of the Corpus Callosum and Hypothalamic-Pituitary endocrine abnormalities. The SOD phenotype is highly heterogeneous and diagnosis is made in the presence of at least two of these three features. Only about a third of these patients have all three features so, patients with any component of the syndrome should be screened for other features too. The cause of SOD is unknown but viral infection, gestational diabetes; environmental teratogens, vascular or degenerative injury and genetic mutations have all been considered as possible predisposing factors. ${ }^{1}$ The condition may be caused by mutation of gene 3p21.2.p21.1 that controls HESX1 (Homeobox containing Transcription Factor) an important regulator of development, particularly of the pituitary. In addition mutation of the neuronal guidance cue netrin and of its receptor DCC has been implicated, but in most cases SOD is a sporadic birth defect of unknown cause and does not 
recur again with subsequent pregnancies. ${ }^{5}$ Patients with SOD may present to medical professional for a variety of reasons. From 6090 percent of these patients present with blindness or symptoms of visual impairment. Signs related to visual loss include absent fixation, searching nystagmus, visual inattentiveness and strabismus. In fact vision testing and screening in young children may reveal the first sign of abnormality. On fundoscopy the optic nerve head is often gray or pale and typically $1 / 2-1 / 3^{\text {rd }}$ of normal size. Classically the optic nerve is surrounded by a ring of visible sclera and annular pigmentation, the 'Double Ring sign'. 6 Three-fourth of patients may have neurologic abnormalities like mental retardation, epilepsy, cerebral palsy or behavioral problems such as attention deficit disorder or autism. The disorder may present with a variety of endocrinologic abnormalities the most common being GH deficiency, followed by TSH, ACTH and vessopresin. GH deficiency manifest as decreased growth rate and neonatal hypoglycemia .Hypothyroidism present as prolonged jaundice, decreased growth rate and developmental delay. Clinical signs related to other hormonal deficiency include hypotension, recurrent infection, seizure, poikilothermia due to hypocortisolism, polyuria and polydipsia due to DI and sometimes precocious or delayed puberty. ${ }^{6}$ If optic nerve hypoplasia is suspected, work-up for other CNS abnormalities is imperative. MRI, the optimal neuroimaging diagnostic tool for CNS abnormalities, provides high contrast resolution and multiplanar images that show the anterior visual pathways distinctly. In SOD, coronal and sagittal MRI scans show a reduction in the intracranial optic nerve diameter, and in those with bilateral optic nerve hypoplasia there is thinning of optic chiasma as well. ${ }^{7}$ A series of 55 patients were divided into 4 groups based on septum pellucidum and hypothalamicpituitary axis appearance on MRI scan:

In group-1 both were normal.

In group-2 there was abnormal septum pellucidum and normal hypothalamic-pituitary appearance.

In group-3 there was normal septum pellucidum and abnormal hypothalamicpituitary appearance
In group-4 both were abnormal.

None of the patients in group- 1 had endocrine dysfunction compared with $22 \%$ in gtoup-2, 35\% in group-3, and 56\% in group-4. Group-2 was most common to experience precocious puberty. ${ }^{8}$ Cerebral hemispheric abnormalities (Schizencephaly, cortical heterotopias) are predictive of endocrinologic deficiencies. Besides MRI, tests of pituitary function should be done to show hypopituitarism. ${ }^{7}$ The patient in our case-report presented with lack of pubertal development, he had amid-facial abnormality corrected at 3 years and diagnosed to have bilateral optic nerve hypoplasia with DI at 6years of age. The unique combination of congenital optic nerve hypoplasia with pituitary endocrine abnormality led us to consider the possibility of SOD. So, we went for hormonal evaluation showing hypogonadothrophic hypogonadism due to panhypopituitarism. MRI of brain showed bilateral optic nerve hypoplasia, other midline brain abnormalities were absent, but interestingly empty sella was found. As two out of three of cardinal feature are required for diagnosis of SOD, so in this case it was established.

Hyot and co-workers first described association of SOD with pituitary dwarfism. ${ }^{9}$ subsequently a large number of endocrine abnormalities due to hypothalamic-pituitary dysfunction have been described. Nayak V, Bhat KR reported a case of 12-yr-old girl with optic nerve hypoplasia and pituitary dwarfism due to SOD in $1991 .{ }^{10}$

SOD patients should preferably be treated by a lifelong multidisciplinary approach to optimize growth and development. Hormonal deficiency needs to be corrected with adequate replacement therapy eg; GH, cortisol etc. Management of puberty requires judgment, which may involve induction of puberty or delaying if premature. Psychomotor retardation complicated by poor vision requires specialist help. Our patient was treated with androgen and cortisol replacement therapy for induction of secondary sexual character and correction of hypocortisolism. He was already on DDAVP therapy for treatment of DI; he is doing well at present and is on regular follow-up. 


\section{Contributors:}

Sharmin-Jahan and Robiul Hasan thoroughly examined and investigated the case under supervision of M A Hasanat and Md. Fariduddin. They prepared the initial manuscript and endorsed important and pertinent references. M A Hasanat and Md. Fariduddin finally formatted the case for publication. Nusrat Sultana and Md. Enayet Hussain helped in preparing the Case report all through. All the authors have gone through and contributed to the final manuscript.

\section{Reference:}

1. De Ferran K, Paiva IA, Gilban DL, et al; Septooptic dysplasia. Arq Neuropsiquiatr. 2010 Jun; 68(3): 400-5.

2. http://www.savantacademy.org/onhqa.php

3. Egan, R.A. and J.B. Kerrison. Opthalmol Clin N Am 2003; 16:595-605.
4. Parker, K et al. J Pediatr Endocrin Metab 2002; 15: 697-700.

5. Dattani MT, Martinez-Barbera JP, Thomas PQ, et al (1998). "Mutations in the homeobox gene HESX1 Hesx1 associated with septo-optioc dysplasia in human and mouse". Nat. Genet. 19(2): 125-33.

6. Lehnstein Campbell, C. Optometry 2003; 74: 417426.

7. Phillips, P.H. and M.C. Brodsky. "Congenital Optic Nerve Abnormalities," in Pediatric Opthalmology and Strabismus, $2^{\text {nd }}$ edition. Edited by Wright, K.W. and P.H. Spiegel (New York: Springer-Verlag, Inc., 2003), 918-922

8. Fard MA, Wu-Chen WY, Man BL, et al; Septooptic dysplasia. Pediatr Endocrinol rev. 2010 Sep; 8(1): 18-24.

9. Hoyt WF Kaplan SL, Grumbach MM. et al: Septooptic dysplasia and pituitary dwarfism. Lancet 1970: I: 893-894.

10. Nayak V, Bhat KR. Septo-optic dysplasia (case report). Indian J Opthalmol 1991; 39: 186-7. 